\title{
Exploring the co-production of digital storytelling for lay knowledge exchange within and between flood risk communities: the case of the River Severn, UK
}

\author{
Andrew Holmes ${ }^{1, a}$, Lindsey McEwen ${ }^{1}$ and Joanne Garde Hansen ${ }^{2}$ \\ ${ }^{1}$ University of the West of England, Bristol, Department of Geography and Environmental Management, Frenchay Campus, Coldharbour \\ Lane, Bristol, UK BS16 1YQ \\ ${ }^{2}$ Centre for Cultural Policy Studies, University of Warwick Coventry, UK CV4 7HS
}

\begin{abstract}
This paper evaluates the potential role of co-produced digital storytelling as a medium of linking flood memories and lay knowledge exchange around flood preparedness for resilience within flood risk communities. The objectives of the described action focus on both process andd output - to capture memory of flood events, and to share critical reflection on, and adaptive learning from, flood experiences within and between communities. Very specific pieces of resilience stories on preparedness were co-produced into digital stories (audio and images) working with individuals and small clusters of people. In the development process, stories were shared within the communities who created them, and within new communities. At all community events, the experience of sharing the stories was observed and evaluated using participant and facilitator questionnaires and independent observation. When shared in community events, the value of the digital media, nature of the story construction, the local or transferable nature of messages, and emotional weight given to the story were all appraised. The stories stimulated new discussions within different community groups and in multi-stakeholder meetings; conversations generated by the same digital story were found to differ depending on the setting. Listeners had high degrees of empathy with the stories gaining insights around 'mobilising community' and 'developing emotional resilience'. The paper explores issues of engagement in order to produce a participatory media -demonstrating the process and tensions of exchanging knowledge, and how the cultural practice of digital storytelling can jump the divide to policymaking and function as a successful way of engaging a wider public at flood risk.
\end{abstract}

\section{Introduction}

Following the severe UK Summer 2007 floods that affected Hull and Gloucestershire, a national report was commissioned [1] that expressed the need to make better use of local knowledge [2]. We argue that the relationship between memories of floods, lay knowledge and resilience to future floods is one approach. In what follows, we offer the conceptprocess-practice of Sustainable Flood Memory [see 3] and draw on Knowledge Exchange through digital storytelling as a form of adaptive learning in 'at risk communities'. This work sits in context of current debates about effective modes and messages in water communication [see 4].

\section{The Sustainable Flood Memories project: earlier research}

From 2011-2013, the interdisciplinary Sustainable Flood Memories (SFM) Project had already gathered semistructured and anonymous interviews from residents in the lower Severn catchment on how they recorded, communicated, maintained or discarded their flood memories in the aftermath of the UK Summer 2007 floods. Having interviewed 65 people and amassed an archive of audio and transcripts of interviews, newspaper scrap books, photographs, videos and letters, the project sought to explore how these archived memories could be exchanged to help encourage 'preparedness' in building community resilience to flooding. A development of the original project (hereafter referred to as the Knowledge Exchange project) focused on trialling digital stories as a medium for exchange of memories and knowledge on flood preparedness within and between communities. The project was developed in collaboration with other stakeholders in flood risk management (environmental regulator, local government, third sector).

\section{Introducing Digital Storytelling and Knowledge Exchange}

Digital stories are constructed of audio (2-3 minutes) and images selected by the author. Digital storytelling was trialled as a method because it had been used in previous research to allow members of communities exposed to a particular risk, for example flooding, to create personal narratives of their risk experience and adaptive learning 
[5]. For example, the Living flood histories project had explored the idea that the participatory flood stories have a potential role to play in community resilience. The Knowledge Exchange project aimed to explore this further by working with communities to co-create digital stories and share them more widely.

\section{Public participation in research}

Callon [6] distinguished between three different "modes" of participation: the Public education model, the Public debate model and the Co-production of knowledge model. In Callon's analysis, these three models of public participation constituted a response to what he saw as a blurring of the boundary between specialists and nonspecialists. In the first - the Public Education model - the public has no direct participation in knowledge production, and must simply trust in a relationship existing between lay people and experts, with the latter driving the knowledge-production process. In contrast to scientific knowledge, local or contextual knowledge has been described as context-dependent, largely communicated through personal interaction and shared experience [7].

The Public Debate model, distinguishes between lay and scientific knowledges but improves relations between lay people and scientists through more open communication. Procedures such as public hearings and focus groups have to be used to gather opinions, thereby muddling to some extent the distinction between specialists and nonspecialists. As a result, there is a comparison of opinions, and the appropriate goal is not education, as in the first model, but the opportunity to exchange viewpoints. It may still exclude lay people from actively participating in the creation of knowledge.

Callon [6] argued that lay people in fact have expertise in their own areas of experience and accumulate knowledge in dealing with daily problems and concerns. The knowledge produced by experts is therefore just as crucial, but it is framed and informed by the knowledge of lay people. This position on co-production accords with a great deal of research in participatory media studies that acknowledge the active audience, the media collector and the importance of community memories. As Gregory and Miller [8] state "lay people mobilise a broad array of tools to solve problems through science, culture, emotion, ethics, morality, trust relationships, and customs. These may be small tools...but they cut through the tangle of contemporary existence and produce solutions that sit more easily with people's lives and consciences" $[8, \mathrm{p}$. $65]$.

\section{The digital story telling process}

Over the course of the Knowledge Exchange project, the strengths and limitations of three different models of digital story creation were explored by working collaboratively with community members:
- Method 1 involved selecting text verbatim from original interviews, discussing with the interviewee, and then co-working to find appropriate images to illustrate the story.

- Method 2 for the co-development of digital stories involved the original narrative being used as a stimulus for the development of a story, which was then captured as audio with images selected by the individual.

- Method 3 developed the model of the community (group) digital storytelling workshop. These workshops were held in three of the original case-study locations within community settings and venues - and acted as stimuli for the generation of new stories.

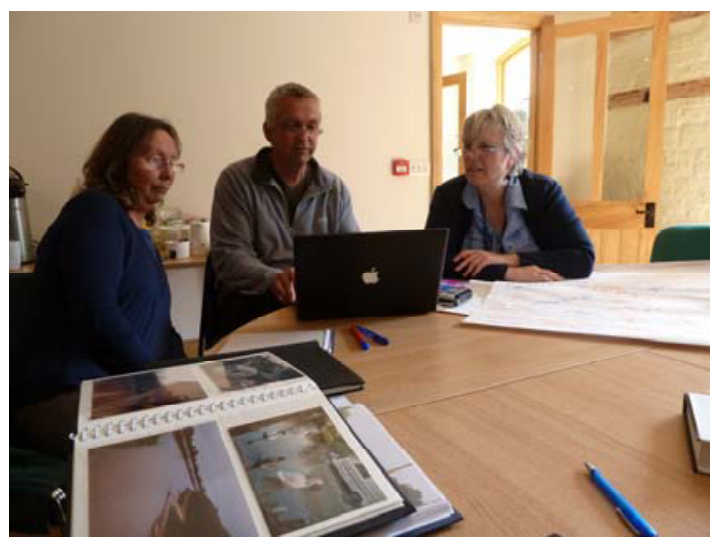

Figure 1. Digital Story-making, community workshop 2014

Together this inter-professional team identified short narratives or vignettes that captured different aspects of preparedness from within the project's original interview transcripts. These nascent 'stories' described and reflected different aspects of 'preparedness for flood risk' viewed through different resilience frames (see Table 1).

\begin{tabular}{|l|l|}
\hline Adaptive resilience & $\begin{array}{l}\text { Leadership and govemance, innovation, situation awareness; } \\
\text { management of vulnerabilities }\end{array}$ \\
\hline Community capital & $\begin{array}{l}\text { Knowing neighbours, extent and exchange of local } \\
\text { knowledge, nature of community groups }\end{array}$ \\
\hline $\begin{array}{l}\text { Emotional/psychological } \\
\text { resilience }\end{array}$ & Individual's ability to cope with stress and adversity \\
\hline Economic resilience & $\begin{array}{l}\text { Employment status, distance to work; home ownership, } \\
\text { insurance, ability to pay for infrastructural changes; levels of } \\
\text { deprivation }\end{array}$ \\
\hline Infrastructural resilience & $\begin{array}{l}\text { Resistance and resilience of property; adjustments to property } \\
\text { to mitigate risk }\end{array}$ \\
\hline Institutional resilience & $\begin{array}{l}\text { Flood experience; engagement with institutional arrangements } \\
\text { for flood resilience, responsibility }\end{array}$ \\
\hline Social resilience & $\begin{array}{l}\text { Age, gender, ethnicity, disability, household size, family } \\
\text { relations, connectivity }\end{array}$ \\
\hline
\end{tabular}

Table 1. Different frames for resilience (building on [9])

Very specific pieces of narrative on preparedness and resilience were then co-produced into digital stories (audio and images), working with individual interviewees and with others in small clusters (2-3 people). 


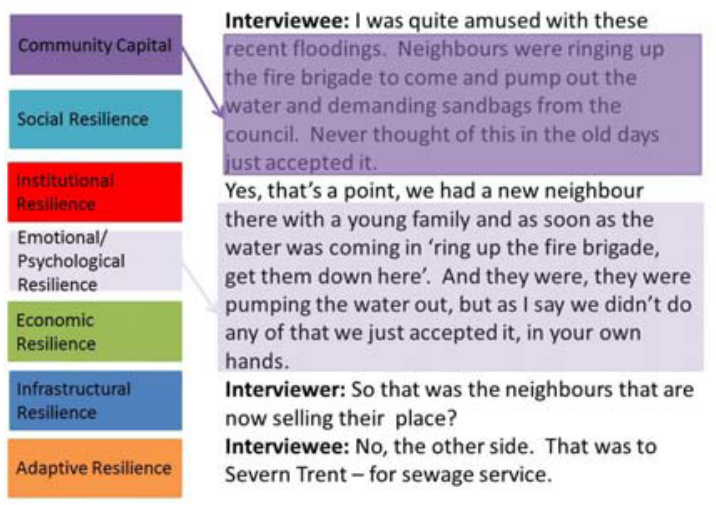

Figure 2. Digital Stories creation - selection of resilience codes

As part of the development process, stories were shared both within the communities who created them, and within new communities. At all community events, the experience of sharing the stories was observed and evaluated in different ways (using participant and facilitator questionnaires and independent observation of the event dynamics). When shared in digital storytelling community events, the value of the digital media, nature of the story construction (simple, layered, nuanced), the local or transferable nature of the message between settings, and empathy levels or emotional weight given to the story were all evaluated. Most digital storytelling research can stop short of the 'sharing' across settings phase and focuses on the production of the story findings in terms of individual transformation. Here, the transformation was being researched in the act of sharing and re-exhibiting in different contexts and through observing and participating in new audience re-readings of the material.

\section{Findings}

The research process highlighted several important factors: the importance of building trust with participants; ethical issues of narrative and authorship; new professional ways of working with digital stories; and sharing flood stories with emotional impact across settings,

\subsection{The value of longitudinal relationships}

Willox and others [10] suggest that digital storytelling "requires that the roles of "researcher" and "researched" begin to change'. Trust, especially the trust among the researchers and those participating, is crucial when using storytelling. Not only that, stability of trust 'enhances the partnership and the project' [10, pp.137]. The process of creating digital stories required a level of trust between the research team and individuals within these communities a trust that developed and enhanced the partnership and the project outcomes. Part of this ongoing trust was the adherence to the co- production of knowledge model - of partnership working to mutual benefit. Participatory and creative media became the glue that bonded researcher and participant.

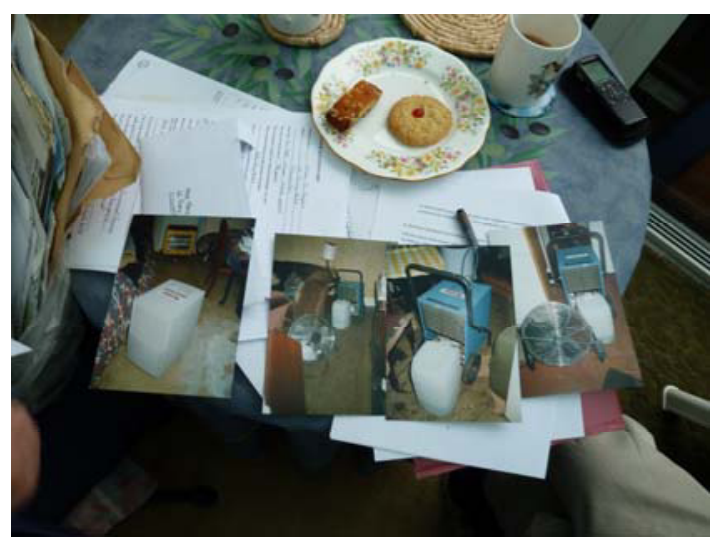

Figure 3. 'Cake, tea and photographs' Creating digital stories in the home

\subsection{The ethical issues of narrative and authorship: my flood memory?}

George Ewart Evans [14, p.127] describes methods like ours as "social therapy" for the interviewees. Evans used this term to refer in particular to an enabling process whereby the older generation who have been "shunted into the scrap heap" transmit their skills just as they did when they were younger $[14$, p.71]. Older members of the community, who remembered historic flood events, were able to share their knowledge and digital storytelling allowing that knowledge to be more easily accessible and distributable to younger generations.

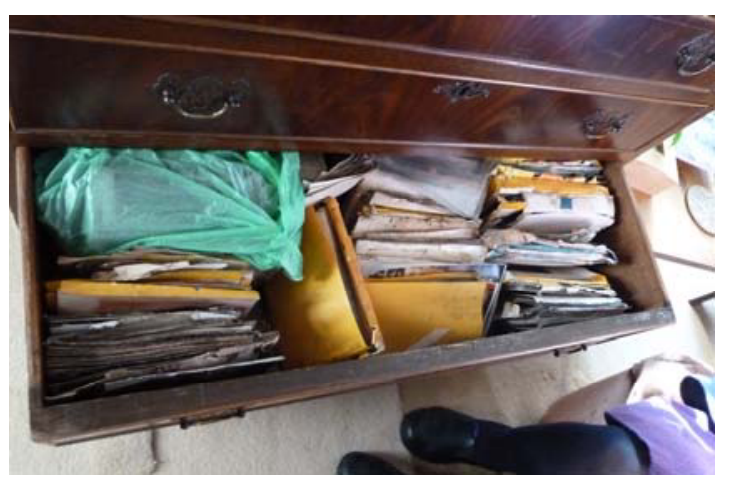

Figure 4. A drawer containing the photographs belonging to the digital storyteller. These photographs were damaged during the 2007 flood.

The subsequent enthusiasm shown in the digital storytelling process suggested that the process was emboldening participants and allowing hidden communities to speak out $[15$, p.282]. Some participants shared many similarities with the participants who Burgess [16], as a researcher on another digital story project, referred to as "wrong side of the digital divide," and who had "never used a computer at all" [16, p.209]. For the interviewees in the SFM project, becoming digital storytellers was something they welcomed, as it gave them an opportunity to continue their work with the project and in doing so continue to "assert their identity" [cf. 17, p.193].

However, in the Knowledge Exchange project, many participants were more than happy to tell their stories and share their images whilst leaving the 'new digital tools' to 
facilitators. As stories developed and moved from the assemblage of audio recordings and archival materials into visual files, this separation from the process, led to a further issue with regard to anonymity. The storytellers, more familiar with hearing their voices in project audio clips and seeing their words in transcript, became aware of the implications of being recorded as a video on YouTube or Vimeo.

However, the question remains how much that knowledge is actionable for less resilient and sometimes younger communities who may be more transient. To whom does the flood memory belong, how much can it be shared, and to what extent is the memory sustainable in the present digital networks and platforms subject to continual change?

Alighed to these questions was another, namely how could these digital supports be preserved, and on which storage platforms? The approach of the Sustainable Flood Memories project was to encompass as many formats for storage as possible, from YouTube to DVD, Twitter to interview transcripts, digital stories to photo exhibitions, Facebook to exhibition posters.

\subsection{Learning about Partnership Working (Digital Storytelling as a new method for agencies)}

In communicating different angles on flood preparedness, it was proposed at the start of the project that digital stories offered two new approaches for flood agencies. The first was the ordinariness of the stories being told and the second was their emotional power. For Thumim [19, p.623], digital storytelling has the potential to "provide the audience with access to the real, and [...] a more authentic reality than that delivered by professionals, precisely because people represent themselves'.

Emotional power would come, not from the visual assault of seeing a violent flood, but instead from the kind of story which would often be disregarded by the mainstream media as trivial and non-dramatic. This was directly addressed by storytellers in telling their ordinary stories, to assert their identity and escape from the confines of dominant narratives generated by mass media, such as "deluge" and "victimhood". As one storyteller had remarked:

'We don't want - and yet we have got - a worldwide, renowned reputation for flooding. And that we don't need and that we don't want. And they trot out this blinking photograph of the abbey surrounded by water.' (RC)

At partnership meetings following the completion of a number of digital stories, agencies had an opportunity to view the stories for the first time and it was the emotional effect of the stories they felt to be the most impactful:

'Our corporate messages tend to be about practical ways of doing things. The whole emotional way of coping with things doesn't really come across, so it's really good that that side is shown.' (Agency member, meeting 2014)

\subsection{Sharing Flood Stories: Emotional impact and the power to provoke}

As part of the Knowledge Exchange project, digital stories were shared by the environmental regulator's engagement teams at environmental regulatorcommunity meetings in areas that were at risk of flooding, and at events including community events, flood fairs and community flood action groups. By taking the critical reflections on flood preparedness that were inherent in the stories and by sharing them in other parts of the country, the environmental regulator felt that a message of the importance of flood preparedness could be more effectively communicated, perhaps in a less formal way.

By the time the digital stories based on the 2007 events were shown in public, some eight years had passed and yet the impact was strong. In remembering that flood, emotional responses become active again. In disaster phases, it is well established that frequently 'emotional highs' and 'emotional lows' occur in collective reactions $[20,21]$. This was particularly evident when trialling the early versions of digital stories at community events held in the locations where the stories had been made. At one event which included a small number of local residents, the screening of a digital story authored by a friend visibly upset one of the viewers, who afterwards remarked to the storyteller "I had forgotten how bad it was for you."

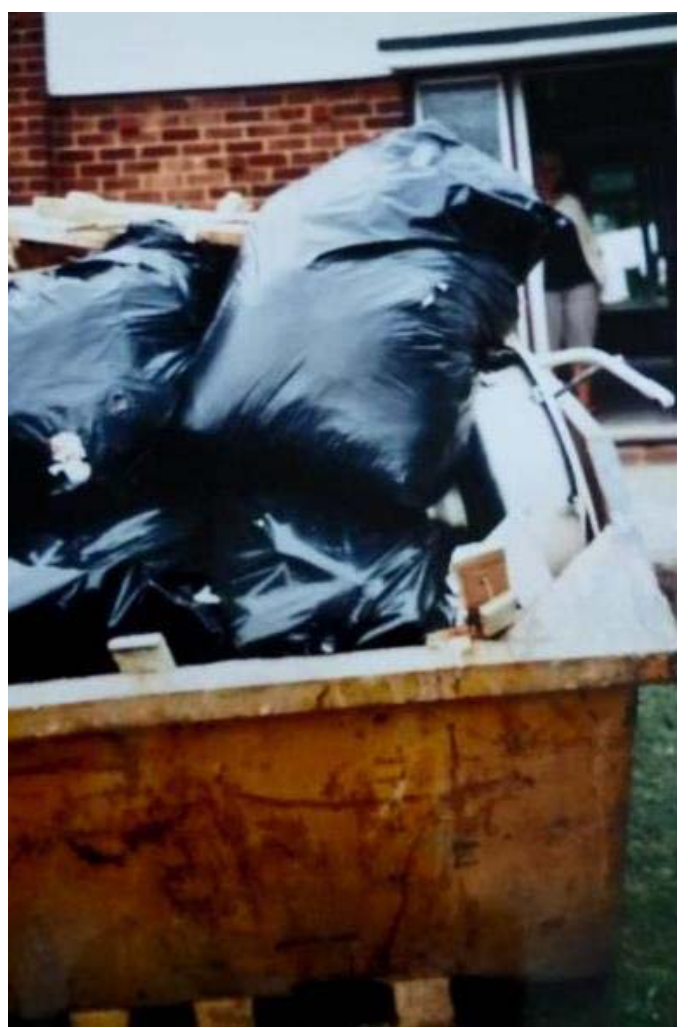

Figure 5. "I had forgotten how bad it was for you." A screenshot from the digital story 
A similar reaction was given as part of the feedback from an officer from the environmental regulator at an early team meeting where the digital stories were shown:

'A very powerful way to engage people about the impacts flooding if they have no prior experience of flooding...I think the films may be too emotive to show to people who have previously been affected by flooding.' (Environmental regulator- Engagement officer, 2014)

The extent of the reaction prompted a change in the project's approach to screenings in the communities that they had been generated in: people in the room were subsequently told of the skeleton content of the story prior to screenings. The power of the stories to evoke powerful memories, however, remained. This was illustrated at another, later, community event when a person, who was asked to describe 'what makes a digital story memorable?' replied: "Remembering my neighbours' suffering."

9. What makes a digital story memorable for you?

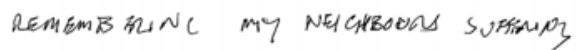

Figure 6. "Remembering my neighbour's suffering." Clip from an evaluation form completed by a participant at a digital story event in December 2014.

The most consistent outcome at events where digital stories were shown was the power of the format to provoke discussion. For members of the community who had attended, this was often an opportunity to engage with agency staff without feeling that they were being "preached to."

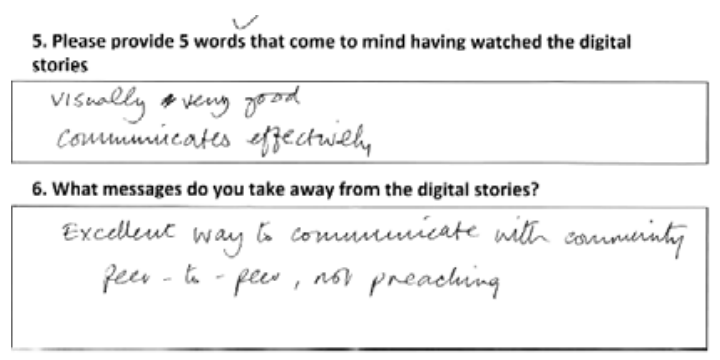

Figure 7. "Peer to peer - not preaching" Clip from an evaluation form completed by a participant at a digital story event in December 2014.

To the FRM agencies hosting the flood events in areas at flood risk, or which had not been flooded in living memory, these story-provoked discussions acted as an effective means of encouraging people to engage with the impacts of flooding and to prepare. This represents a lower level form of truth and reconciliation between community and agencies.
'What I am liking about the videos is, because they are a personal account, they are not too structured and not too corporate [unlike] the one's we have tried before as an organisation, which I think haven't quite hit the mark because they have felt a bit staged, where we have tried to cram in our core messages around safety and everything. I like these because they are points of discussion: they are not going to have all the answers in a two minute clip but they are helping people to think. If we want to generate discussion and thinking within people, this feels like a good way of doing it.' (Agency partner).

\section{Implications}

The project found that a participatory narrative media approach to environmental communication with lay/local knowledge sharing had significant value for knowledge exchange when placed alongside, or integrated with, other forms of 'expert knowledge'. This was achieved by drawing upon the longitudinal engagement that had taken place between the researchers and members of the public in the catchment. Through this relationship and trust the Knowledge Exchange project, and the strong foundation from which it emerged, was able to respond to the subsequent challenges, such as those around ethics and fear/mistrust of media and new technologies.

If longitudinal engagement provided the project with a foundation of trust and goodwill on which to build then conversely, the internal politics of the environmental regulator was a factor that acted against the sustainability of digital memories. For example, during the course of our research, the regulator - faced with large scale redundancies and the associated movement of staff - was forced to constantly adapt its IT competencies. As a result, we found examples of flood archives going missing and the dislocation of personnel who had developed strong, local ties and understanding and appreciation of digital storytelling.

The process of creating digital stories enabled voices in flood risk areas to be heard but also to be transmitted so that the completed stories then became powerful stimuli which could be shared by agencies in areas that may be flooded in the future. The power of the emotional weight of stories was enhanced by the method in which they were transmitted (digital stories) and this led to a degree of empathy with the stories (within and between communities).

It should be noted that sharing of the digital stories online requires capabilities not available in all communities or their communal spaces. DVDs mitigated against these issues. The sharing of stories with communities may also require revised protocols for digital resource sharing within FRM organisations.

Issues remain in a changing media environment in which generational use of different forms of media 
(social, digital and analogue) require continual convergence and re-engagement across scales. The Flood Memory App project being developed at the University of Warwick, UK is one example of how the digital memories of the Sustainable Flood Memories project are being sustained after the latter was completed. However, any software development of a digital repository has to balance issues of future proofing the digital memory within an environment of constant updates, open source, new plug-ins or continuous web management if the repository is custom built rather than 'off the shelf'. Our research took the widest possible multi-stakeholder approach, drawing together existing social media networking sites (Facebook, Twitter, Youtube) with institutional memory organisations (local archives, regional media) incorporating personal and community collections (in analogue and digital formats). The digital stories were an important sustainability practice for the community participants, local archivists, water governance agents and regional/national repositories.

\section{Acknowledgements}

This research was funded by UK Economic and Social Research Council Grant: ES/K00767X/1. The authors thank all participants in the project and Katherine Jones for assisting in independent observation of community workshops.

\section{References}

1. UK Cabinet Office (2008). The Pitt Review: Lessons learned from the 2007 floods (http://www.cabinetoffice.gov.uk/thepittreview.aspx) 2. Haughton, G., Bankoff, G., and Coulthard, TJ. (2015). In search of 'lost' knowledge and outsourced expertise in flood risk management. Transactions of The Institute Of British Geographers, 40(3), 375-386 3. McEwen, L. J. and Jones, O. (2012). Building local/lay flood knowledges into community flood resilience planning after the July 2007 floods, Gloucestershire, UK. Hydrology Research, Special Issue 43, 675-688.

4. Water Communication (2014)

http://www.iwawaterwiki.org/xwiki/bin/view/Articles/ WaterCommunicationAnalysisofStrategiesandCampaig nsfromtheWaterSector

5. Krause, F., Garde-Hansen, J. and Whyte, N. (2012).

Flood memories media, narratives

and remembrance of wet landscapes in England,

Journal of Arts \& Communities, 2012, (4)

Numbers 1 \& 2, 129

6. Callon, M. (1999), "The role of lay people in the production and dissemination of scientific knowledge", Science, Technology and Society, 4, 81-94.

7. Morgan, K. and Murdoch, J. (2000), “Organic vs. conventional agriculture: knowledge, power and innovation in the food chain", Geoforum, 31, 159-173.
8. Gregory, J. \& Miller, S. (2001), "Caught in the crossfire? The public's role in the science wars", In: Labinger, J. and Collins, H. (editors), The one culture?, University of Chicago Press pp. 61-84.

9. Cutter, SL., Burton C.G., and Emrich C.T (2010)

'Disaster Resilience Indicators for Benchmarking Baseline Conditions', Journal of Homeland Security and EmergencyManagement, 7(1): 1-22.

10. Willox, A., Harper, S. and Edge V., 'My Word': Storytelling and Digital Media Lab and Rigolet Inuit Community Government (2013) Storytelling in a digital age: digital storytelling as an emerging narrative method for preserving and promoting indigenous oral wisdom Qualitative Research 13 (2) 127-147

11. Landström, C., Whatmore, S.J., Lane, S.N, Odoni, N.A., Ward, N. and Bradley, S. (2011) Co-producing flood risk knowledge: redistributing expertise in critical 'participatory modelling' Environment and Planning A 43 1617-1633

12. Thomson, A. 'Making the most of memories: The Empirical and Subjective Value of Oral History', Transactions of the Royal Historical Society, 9, 1999, 291-301.

13. Hendry, P.M. (2007) The future of narrative, Qualitative Inquiry, 13, 487-497

14. Evans, G.E. (1970), 'Approaches to Interviewing', The Journal Of The Oral History Society, 1(4), 1970, 56-71.

15. Mark Riley, M., and Harvey, D. (2005),

'Landscape Archaeology, Heritage and the Community in Devon: An Oral History Approach', International Journal of Heritage Studies, 11 (4), 269-288.

16. Burgess, J. (2006), Hearing Ordinary Voices:

Cultural Studies, Vernacular Creativity and Digital Storytelling, Journal of Media \& Cultural Studies, 20 (2), 201-214

17. Meadows, D. (2003), Digital Storytelling:

Research-Based Practice in New Media Visual Communication 2 (2), 189-193

18. Frisch, M., Abraham, J., Suchanek, J. and Dean, P. (2005), Media Reviews. Oral History

Review, 32, 89-100

19. Thumim, N. (2009), 'Everyone has a story to tell' Mediation and self-representation in two UK institutions, International Journal of Cultural Studies, 12 (6), 617-638

20. Klaebe, H.G., (2013), Facilitating local stories in post-disaster regional communities : evaluation in narrative-driven oral history projects, Oral History Journal of South Africa 1, 125-142

21. UK Health Protection Agency, (2011), The effects of flooding on mental health (www.alnap.org/pool/files/master-mental-health-2-dec'11-with-logo.pdf) Accessed 10 February 2016 